\title{
Sarah E. Morgan appointed JMR Associate Editor for Polymers and Organic Materials
}

\author{
mrs.org/jmr
}

$\mathrm{T}$ The Journal of Materials Research Editor-in-Chief Gary L. Messing is pleased to announce the appointment of Sarah E. Morgan as Associate Editor for Polymers and Organic Materials. "Professor Morgan is an outstanding leader in the field of polymeric materials with an extensive record of research accomplishments and experience in both industry and academia," remarked Messing. Morgan is a professor and associate director of the School of Polymer Science and Engineering at The University of Southern Mississippi (USM).

Prior to joining USM, Morgan worked at GE Plastics in R\&D and research management in engineering thermoplastics, where she developed new copolymers, polymer blends, composites and nanocomposites for automotives, electronics, medical products, and building and construction applications. Her current research focuses on surface and interface modification, involving high-performance polymers, composites, nanocomposites, and bioinspired materials. A longtime active member of the Materials Research Society (MRS), Morgan has received several honors, including the Journal of Polymer Science Part B: Polymer Physics Prize in 2010 and the Society of Plastics Engineers Education Award in 2015. She was named a POLY Fellow by the Polymer Chemistry Division of the American Chemical Society (ACS) in 2016. She is also the 2019 chair of the Polymer Chemistry Division of the ACS.

"The JMR editorial team looks forward to working with Professor Morgan to publish the growing and diverse range

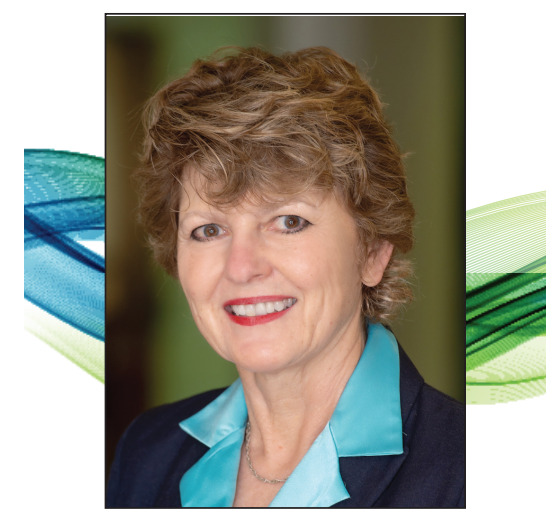

of polymeric materials and applications presented by the MRS community at Materials Research Society meetings and from prestigious institutions worldwide," said Messing.

For more information about $J M R$, visit mrs.org/jmr.

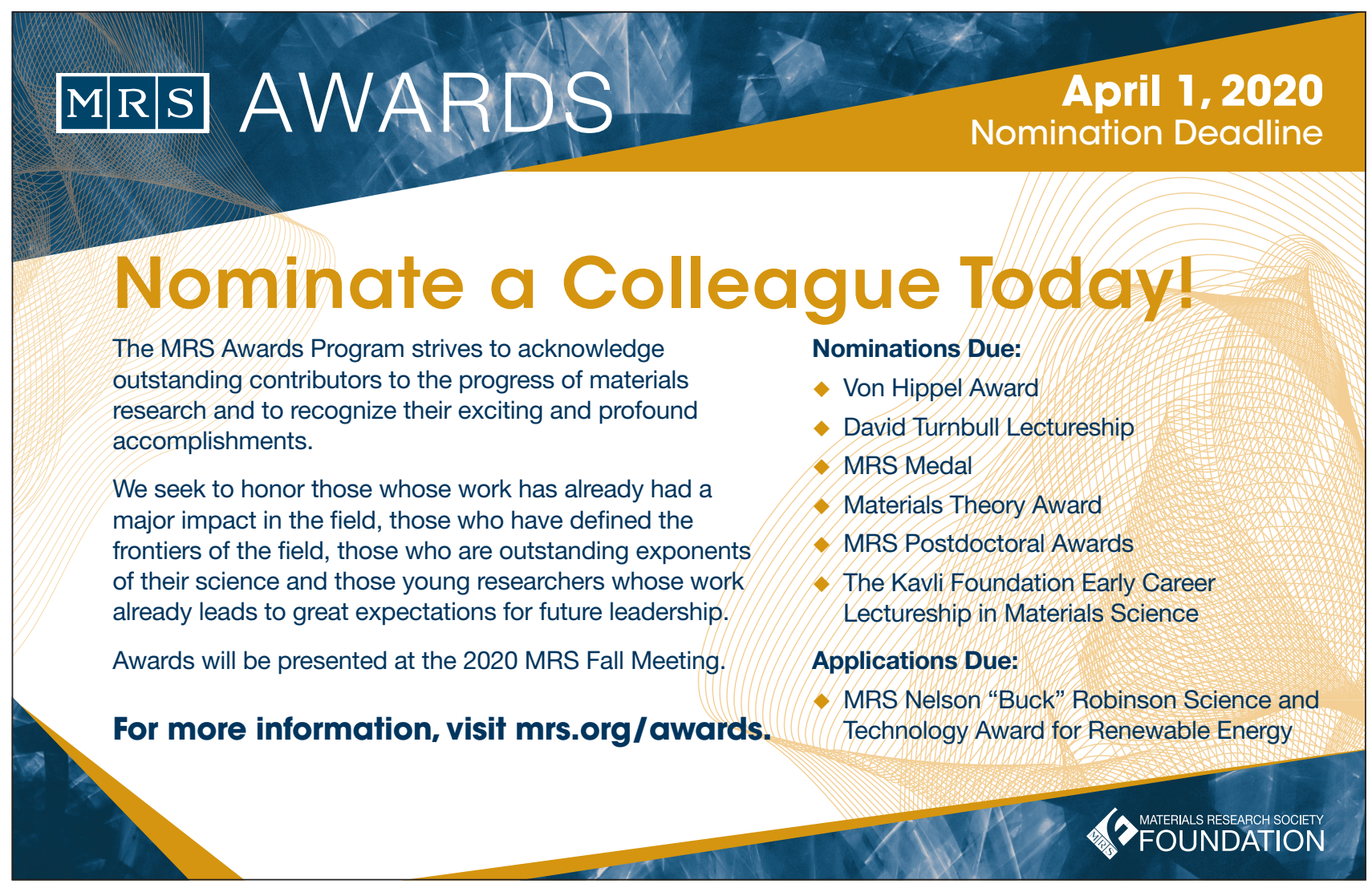

